\title{
APROXIMACIÓN A LAS REFERENCIAS METATEATRALES EN LOS FINALES DE LAS COMEDIAS CALDERONIANAS ${ }^{1}$
}

\author{
Zaida Vila Carneiro \\ Departamento de Filologías Hispánica y Clásica \\ Edificio de Filologías \\ San José de Calasanz 33. Universidad de la Rioja \\ 26004 Logroño (La Rioja). España \\ zaida.vila@unirioja.es \\ Alicia Vara López \\ Facultad de Ciencias de la Educación \\ Avda. San Alberto Magno s/n. Universidad de Córdoba \\ 14071 Córdoba. España \\ avara@uco.es
}

La literatura del Siglo de Oro se caracteriza por el gusto por la artificiosidad y el juego y se alimenta muchas veces de la reflexión metaficcional para facilitar guiños que irían dirigidos a un receptor ávido de referencias de las que participaría. En el caso del teatro calderoniano, estas alusiones reflejan en muchas ocasiones la situación comunicativa en la cual una obra es representada, siguiendo una serie de convenciones

${ }^{1}$ El presente trabajo se enmarca en el Proyecto de Investigación de la DGICYT dirigido por Luis Iglesias Feijoo FFI2012-38956, y en el Proyecto Consolider-Ingenio CSD2009-00033 sobre «Patrimonio teatral clásico español» TECE-TEI, conocido como TC-12, cuyo coordinador general es Joan Oleza, de la Universitat deValència, que reciben fondos FEDER. Asimismo, forma parte del proyecto «Secrets and Secrecy in Calderón's Comedies and in Spanish Golden Age Culture. Including a Critical Edition of El secreto a voces» (P 24903-G23), financiado por Austrian Science Fund FWF y dirigido por Wolfram Aichinger en la Universidad de Viena. 
y procedimientos bien conocidos por todos los participantes ${ }^{2}$. Los finales de las comedias facilitan de manera especial la apertura de un canal de comunicación directo entre el autor y el espectador, generalmente a través de las palabras del gracioso, que, de forma convencional, rompe la ilusión teatral para poner sobre la mesa el producto comercial en el que él mismo está inmerso ${ }^{3}$.

Otras veces los últimos versos son presentados por otros personajes, de manera individual o coral, conforme al gusto calderoniano por los contrastes y la polifonía. De hecho, existe cierta flexibilidad en la selección de los últimos locutores, aquellos encargados de mirar directamente al público en un gesto similar al aparte para poner el broche final a la representación. En su boca se registra una serie de elementos constantes y en gran medida homogéneos que serán objeto de análisis en este trabajo. Se trata de referencias a la propia obra, a su conclusión y a distintos participantes de la puesta en escena, como los comediantes, el público o el autor, las cuales —al lado de otros elementos como la métrica o la música - incitarían al público a materializar el aplauso.

Este artículo pretende ser un punto de partida para el estudio de la metateatralidad en el cierre de las comedias de Calderón; para ello y con el objetivo de obtener cuantos más datos sean posibles y así dictaminar la evolución de su modus scribendi, hemos examinado 73 piezas: en concreto, La selva confusa, considerada en la actualidad la primera comedia del dramaturgo madrileño, y las 72 obras que se incluyen en las seis primeras partes de Comedias publicadas en 1636, 1637, 1664, 1672, 1682 y 1683 respectivamente. Así pues, trabajaremos con un corpus compuesto por piezas teatrales confeccionadas entre 1623 (como La selva confusa, Amor, honor y poder o Judas Macabeo) y 1680 (como Hado y divisa de Leonido y Marfisa), las cuales abarcan temporalmente la totalidad de la carrera dramatúrgica calderoniana.

Una vez establecido el corpus, el objetivo principal es realizar una taxonomía de los parlamentos finales de las comedias, basada en la ex-

${ }^{2}$ Para un estudio de los recursos metaliterarios como fuente de comicidad en el teatro calderoniano puede verse Iglesias Feijoo, 2002.

${ }^{3}$ Bravo Villasante, 1944,pp. 264-268, y Pailler, 1980, reflexionan acerca de la ruptura de la ilusión escénica que presenta habitualmente el personaje del gracioso en la comedia áurea. En la misma línea, Hermenegildo, 1995, p. 231, caracteriza al gracioso como «un personaje marginal en la fábula» que «encuentra una solidaridad en el espectador». Para un análisis de las fórmulas de cierre de las comedias calderonianas en relación con la interpretación de la figura del gracioso, véase Lobato, 2005. 
tracción, ordenación y sistematización de las fórmulas estereotipadas relacionadas con la huella metaliteraria, a la vez sello de identidad del dramaturgo y marca del espíritu lúdico barroco.

\section{Del autor y SU PUesta EN ESCEnA}

En el repaso por los distintos participantes del circuito teatral retratados en los cierres de las comedias resulta muy llamativa la aparición de la figura del artífice de la pieza, señalado como uno de los responsables de su éxito o fracaso. Después del desfile de personajes y acciones a lo largo de las tres jornadas, el autor de la obra aparece en algunas ocasiones aludido en los últimos versos y pasa a formar parte de la ficción como agente indirecto de una reflexión autocrítica sobre el propio producto dramático. Esta tendencia a la exposición del dramaturgo al juicio del público se constata de manera recurrente en las obras compuestas por un Calderón joven que se introduciría, de forma más o menos deliberada, en el universo literario creado, llegando a codificarse a sí mismo como una fórmula más de la conclusio. Mediante esta suerte de sello personal o firma, dirigida de forma explícita al público, el autor, desde el momento de la escritura, pone de manifiesto la proyección espectacular de sus comedias ${ }^{4}$.

Si se atiende a las fórmulas explícitas empleadas para este tipo de menciones en el cierre de las comedias, la más frecuente y rentable es el sustantivo autor, localizado en siete ocasiones (La devoción de la cruz, La dama duende, Peor está que estaba, Judas Macabeo, Hombre pobre todo es trazas, La sibila de Oriente y la gran reina de Saba y Gustos y disgustos son no más que imaginación). Todo apunta a que con este membrete se alude al dramaturgo, pues es él mismo el que escribe la obra y parece razonable que se identifique como el responsable último. No obstante, cabe tener en cuenta que en la época el término autor también podía referirse a lo que hoy se denominaría director teatral. Resulta dificil determinar a cuál de las dos figuras se aludiría en cada caso y no se descarta un uso deliberadamente ambiguo o ambivalente del término, teniendo en

\footnotetext{
${ }^{4}$ En palabras de Rubiera, 2005, p. 12: «El poeta dramático se preocupa por prever el desarrollo de la ficción en un espacio escénico, pensando en el efecto que se producirá sobre un espectador, mejor, sobre muchos espectadores. En este sentido, el trabajo del dramaturgo se orienta en dos direcciones: proporcionar los datos de la construcción imaginaria del espacio de la ficción y dar las indicaciones, de modo más o menos directo y preciso, para una representación».
} 
cuenta que se introduce en el momento previo a la emisión del juicio del auditorio.

En cambio, carece de toda duda referencial la segunda mención por orden de frecuencia, la del poeta. Esta figura, identificada con el dramaturgo, se localiza en cinco de las comedias analizadas (El mayor encanto, amor, Origen, pérdida y restauración de la Virgen del Sagrario, Los tres mayores prodigios, No hay burlas con el amor y Amigo, amante y leal). Una variante más indirecta de esta fórmula es la expresión "quien (le) ha escrito», registrada en El sitio de Bredá y Dicha y desdicha del nombre.

\section{De LA COMEDIA Y SU DICHOSO FIN}

Como es bien sabido, introducir el título de la comedia en el cuerpo del texto era una práctica recurrente en el teatro del Siglo de Oro, de ahí que abunden las piezas que presentan paratextos octosilábicos, por ser este el metro más habitual en el teatro del siglo XviI. Algunos ejemplos de este hábito en la producción calderoniana son, entre otros, La devoción de la cruz, Amor, honor y poder, El médico de su honra, Los tres mayores prodigios, La púrpura de la rosa, El monstruo de los jardines, El José de las mujeres, Dicha y desdicha del nombre o El mágico prodigioso. De hecho, la inclusión metateatral de los títulos, dispuesta a modo de guiño para los espectadores, facilitaba cierta circularidad o simetría a la comedia, que se cerraría con la referencia al mismo (o similar) título que la precede.

El título suele localizarse en los últimos versos y puede presentarse de manera literal o con ligeras variantes. De las 73 piezas calderonianas examinadas solo 21 carecen de este tipo de autorreferencia. Por norma general, se ha comprobado que el título se presenta íntegro y ordenado, así sucede en 32 de las 52 comedias, pudiendo ocupar un verso completo, como ocurre en Lances de amor y fortuna, Mañanas de abril y mayo, El postrer duelo de España o Los dos amantes del cielo, por citar algunos ejemplos, o combinándose con otras palabras para alcanzar un metro determinado. Este último caso se aprecia, por ejemplo, en La Puente de Mantible, cuyo paratexto consta de siete sílabas, por lo cual Calderón ajusta el cómputo métrico introduciendo el adverbio hoy, o en La hija del aire, segunda parte, donde el octosílabo se consigue añadiendo porque de antes del título de la comedia. De manera menos habitual, el título se extiende a más de un verso, véase Dicha y desdicha del nombre ("Y si la dicha $y$ desdicha / del nombre dio este suceso»). 
En otras ocasiones más escasas (La aurora en Copacabana y Fineza contra fineza $a^{5}$ ) se registran ejemplos en los que un final de obra musical propicia la reiteración del título. Sin embargo, no es posible establecer ninguna generalización al respecto, puesto que esta circunstancia no parece ser exclusiva de las piezas que se cierran con música, ya que, por ejemplo, en Basta callar se reitera cuatro veces el título sin cumplirse la premisa musical y lo mismo sucede en Para vencer a amor, querer vencerle, donde el paratexto aparece en dos ocasiones. Esta inclusión repetitiva del título de la propia obra representada a lo largo de la pieza podría obedecer a una finalidad propagandística que entroncaría con el deseo de que el espectador la retuviese en su memoria.

Como ya se ha avanzado, en el final de diversas comedias el título sufre pequeñas modificaciones que pueden ser debidas a distintos motivos. Uno de los más habituales es el deseo de amoldarlo a una determinada forma métrica. Estas alteraciones pueden llevarse a cabo de distintas maneras, por ejemplo cambiando de orden los términos que configuran el paratexto. Muestra de ello son Argenis y Poliarco, en donde se invierte el título para ajustar el octosílabo y mantener la rima (e-e), con una ligera variación (e-i); Eco y Narciso, cuyos términos son también cambiados de orden por razones de métrica y rima; y Amor, honor y poder, en la que el trueque de los miembros que configuran el título resulta necesario para ajustarse a un endecasílabo.

Mucho más común es el acortamiento, es decir, la presentación de los títulos al final de la obra, pero de manera parcial.Véase, por ejemplo, Casa con dos puertas mala es de guardar, a cuyo término figura solo la primera parte del paratexto, que se inserta en una frase preposicional que sirve para completar el octosílabo $;$ El sitio de Bredá, donde se registra una referencia acortada al título a través de la palabra clave que permite al espectador identificarlo (Sitio) y que, asimismo, indica que el asedio de la ciudad también ha concluido; y El hombre pobre todo es trazas, final en el cual el paratexto se acorta para ajustarse al octosílabo y actúa sintácticamente como complemento directo del verbo ser («ser el hombre pobre trazas»).

${ }^{5}$ En esta última comedia el sintagma que se repite es Finezas contra finezas, es decir, se altera el paratexto pasándolo de singular a plural.

${ }^{6}$ El espectador identificaría el título completo a partir del sujeto de la cláusula que lo conforma. 
Se ha comprobado también que, exceptuando el caso de Dicha y desdicha del nombre, cuando el título se distribuye en dos versos suele sufrir alguna leve alteración derivada de su integración en la estructura sintáctica y métrica que corresponda. Así sucede en $A$ secreto agravio, secreta venganza, donde, para mantener la rima, se invierte el orden de los miembros del segundo sintagma, al cual se añade el adverbio de afirmación también, que sirve para ajustar el segundo octosílabo («por dar a secreto agravio / también venganza secreta»); Los hijos de la fortuna, Teágenes y Cariclea, en la cual Calderón prescinde del artículo determinado femenino para, nuevamente, lograr un verso de ocho sílabas («de Los hijos de Fortuna, / Teágenes y Cariclea»); y Gustos y disgustos son no más que imaginación, pieza que a su término modifica también por cuestiones de rima su título ("que el gusto y disgusto son / no más que imaginación»). Detrás de estos cambios, además del principal propósito sintáctico o métrico, se alza la voluntad del dramaturgo de exprimir y manipular sus conceptos con virtuosismo, especialmente en lugares estratégicos de la obra como los finales.

Casos especiales son los de obras como El Príncipe Constante, Judas Macabeo y El Faetonte. En estos tres textos, el título — que focaliza la atención en el protagonista - ya deja clara la relevancia que tendrá dicho personaje en la trama de la comedia y en su desenlace final. Estas figuras, de indudable peso dramático, a menudo se identifican por medio de epítetos que aluden a sus características esenciales. En El Príncipe Constante se introduce el nombre del príncipe, encabezado por el adjetivo católico, destacándose de este modo, además, una lectura religiosa de la comedia. La aposición amplificadora "príncipe en la fe constante» resume la trayectoria del personaje a lo largo de la obra y su perseverancia en la fe («El católico Fernando, / príncipe en la fe constante»), al mismo tiempo que se busca el recurso de la acumulatio para ponderar sus virtudes. En el cierre de Judas Macabeo, el título se modifica en los versos finales sustituyendo de forma metonímica el nombre del protagonista por un adjetivo que alude a su fortaleza («Y del fuerte Macabeo»), de forma que queda manifiesto su poderío frente a las adversidades. Es digno de mención también el caso de El Faetonte, el título que figura no es literalmente el de la comedia ni tampoco el que constaba en algunos manuscritos de la misma, y, en su lugar, se adopta la variante apocopada Faetón, seguida de su habitual vinculación al sol (hijo de Apolo). El verso bimembre destaca la relación paternofilial del protagonista con el 
mismísimo astro rey, de forma que se exalta, una vez más, el valor del personaje.

Menos frecuentes son los casos de amplificatio, en los que el título aparece desarrollado con la finalidad de reformular los sucesos acaecidos en la comedia. Es lo que ocurre en La selva confusa, donde el paratexto se muestra claramente alterado, de forma que la atención pasa de centrarse en el espacio (la selva) para recaer en la confusión («la confusión que en esta selva ha habido»). En otras ocasiones y también poco habitualmente, las modificaciones que sufre el título parecen responder a una síntesis de la obra, como podemos ver en También hay duelo en las damas, cuya ligera variación del paratexto no es debida a la métrica («porque hubo duelo en las damas»), en No hay burlas con el amor («burlas de amor, que son veras») y en Saber del mal y el bien ("de que sabré, pues ya supe / del bien y del mal»).

Otros cambios que parecen no esconder ninguna implicación ni métrica ni simbólica se localizan por ejemplo en El astrólogo fingido, donde se sustituye el artículo determinado por el indeterminado; El mágico prodigioso y El encanto sin encanto, que muestran la contracción del determinante con la preposición a; y Mejor está que estaba, título que sufre una ligera alteración en el orden de los componentes que lo configuran («hoy está mejor que estaba») sin ninguna razón aparente.

Del mismo modo, cabe poner de manifiesto que el título de la comedia se ubica, de manera general, en el último parlamento del gracioso, como sucede en Eco y Narciso, El monstruo de los jardines o Gustos y disgustos son no más que imaginación; o de algún otro miembro de baja condición social, sirva como ejemplo El encanto sin encanto, donde el personaje que da término a la obra es Libia, una de las criadas. Cuando esto no ocurre, el convencional cierre suele articularse de manera coral, por lo que esta referencia a la obra aparece en boca de todos o casi todos los personajes (Hado y divisa de Leonido y Marfisa) o en diálogo, como en $\mathrm{La}$ niña de Gómez Arias, que finaliza con una conversación entre don Diego y don Félix, en la que este último pronuncia el título de la comedia ${ }^{7}$.

En este afán calderoniano por la concentración de elementos metateatrales en la conclusio, resulta comprensible la tendencia a la mención de la propia obra representada, ya sea por medio del título, como hemos visto, o, de forma menos habitual, mediante referencias más genéricas. Este último tipo de alusiones figura en 26 de los 73 casos analizados y

\footnotetext{
${ }^{7}$ Recordemos el gusto de Calderón por la polifonía, la diversidad y los contrastes.
} 
se registra bastante variedad en las etiquetas con las que se denomina a la pieza. Lo más común, localizado en 15 de las obras que configuran el corpus utilizado, es referirse a ella como "la comedia», empleando el artículo determinado, que encaja con el conocimiento general del referente espectacular y verbal que acaba de ser desplegado ante el público. También aparece la alusión a la obra como «la historia» (El purgatorio de san Patricio), "verdadera historia» (A secreto agravio, secreta venganza, Gustos y disgustos son no más que imaginación) o "su historia» (En la vida todo es verdad y todo mentira, La hija del aire, segunda parte) en una serie de formulaciones que ponen de manifiesto el componente narrativo ${ }^{8}$. En relación con esta misma visión de la pieza como un relato, figuran otras tantas fórmulas: «este suceso» (Dicha y desdicha del nombre), "su fábula» (La púrpura de la rosa), "prodigioso asunto» (El José de las mujeres) y "las fortunas» (La gran Cenobia, Argenis y Poliarco, Andrómeda y Perseo), que a menudo ponen el acento en la naturaleza extraordinaria de las aventuras vividas por los personajes.

No obstante, este señalamiento ponderativo del producto que está siendo representado no cobraría todo su sentido en los finales de las comedias sin el propósito de indicar que está llegando a su término, por lo cual son muy destacadas las alusiones explícitas a su conclusión. Las estructuras más rentables son aquellas construidas alrededor del propio sustantivo fin -Dar / tener / poner (dichoso) fin-o las que hacen mención del verbo acabar en sus distintas formas?.

Otro aspecto relacionado con este tipo de elementos es el del anuncio o promesa de que se publicará (o representará) una segunda parte de la misma. Se trata de una concepción no definitiva del fin, en la cual se entiende que el tema de la pieza no está agotado y puede cristalizar en otra comedia que el dramaturgo quiere publicitar. Esto sucede en tres de las 73 obras que hemos analizado: La hija del aire, primera parte; Apolo

${ }^{8}$ En el siglo XVII la narrativa y la comedia son contempladas por escritores y preceptistas como textos afines, a pesar de tratarse de dos sistemas semióticos diferentes con sendos puntos de vista narrativos. Por ello es muy frecuente el diálogo entre prosa y comedia y las referencias entrecruzadas a ambos géneros. De hecho, Avellaneda, 2011, p. 105, en el prólogo a El ingenioso hidalgo Don Quijote de la Mancha (El Quijote apócrifo), considera que "casi es comedia toda la historia de don Quixote de la Mancha».

${ }^{9}$ Al lado de estas fórmulas prototípicas, se aprecia la presencia de otras más originales, como la que nos brinda Los hijos de la fortuna, Teágenes y Cariclea, donde figura la expresión «Sirva de remate / embebido». 
y Climene y Judas Macabeo. De las dos primeras sí se conoce la existencia de una continuación de la obra, no así de Judas Macabeo.

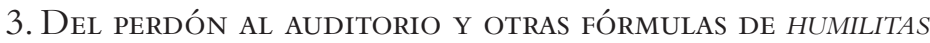

En relación con las reglas clásicas de la retórica, es muy común en los cierres de comedias «la petición de perdón de faltas, que responde a la captatio benevolentiae propia de la conquestio» ${ }^{10}$. Este tipo de formulaciones va orientado a la búsqueda de la aprobación del público y, en definitiva, a su predisposición en favor del aplauso final. En muchas ocasiones se ponen en boca del autor o poeta, si bien el que las pronuncia en las tablas es un personaje de la comedia, que se disculpa en nombre de todos los participantes. Generalmente es el propio gracioso, caracterizado por su cercanía con el público, quien trata de influir positivamente en la opinión de la audiencia en este momento previo al aplauso o al abucheo. En el corpus analizado se han localizado numerosas referencias a la solicitud de perdón (41) por los yerros (14), las faltas (16), los defectos (2) o los errores (1) cometidos. Otras veces se pide piedad (1) o que se suplan las posibles tachas con la alegría de las bodas o con una segunda parte de la comedia (2).

No obstante, la afectación con la que se pronunciarían dichas disculpas y la codificación de las estructuras en las que se insertan apuntan a que se trata de una fórmula de falsa humilitas, que entronca con la artificiosidad y el espíritu lúdico de la comedia nueva. De hecho, resulta muy llamativa, e incluso hiperbólica, la recurrente mención de un autor arrojado a los pies del público que da muestra de su sometimiento a los dictados de la audiencia.

En este mismo sentido, se registra en numerosas ocasiones la expresión "a los pies de Vuestra Merced», que en los finales de las comedias sirve para incluir al receptor del producto dramático y poner de manifiesto una vez más su relevancia en la concepción y desarrollo del espectáculo. Esta particularidad se puede apreciar en el hecho de que el poeta es caracterizado de manera reiterada como «humilde servidor» del público, postrado «a los pies» o (metonímicamente) «a las plantas» de la audiencia. La figura receptora de esta reverencia llega a ser en algún caso, de forma literal o figurada, el propio monarca, al que se apela mediante fórmulas estereotipadas que sugieren una puesta en escena en palacio:

${ }^{10}$ Lobato, 2005, p. 257. 
«a esos reales pies» (El maestro de danzar), «a esas reales plantas» (El postrer duelo de España), «a vuestras plantas invictas» (Agradecer y no amar). En el caso de Amor, honor y poder es el rey de la comedia, Eduardo III, el que sustituye ficcionalmente a su correlato en la audiencia, ya que Enrico besa sus pies y así pone el broche final a la representación: "Que me dejes besar tus pies suplico / por que, a tus plantas puesto, / poder, amor $y$ honor den fin con esto".

En este afán por la autorreflexión teatral y la valoración del propio producto dramático resultan muy llamativas las interpelaciones directas a la audiencia, que se codifican como una de las fórmulas de cierre ${ }^{11}$. Dichas alusiones explícitas al receptor de la obra por parte de los personajes tienen lugar, en sentido riguroso, en tan solo 6 de las 73 piezas que configuran nuestro corpus: Saber del mal y el bien, Peor está que estaba, Lances de Amor y Fortuna, La hija del aire, primera parte, Gustos y disgustos son no más que imaginación y Dicha y desdicha del nombre.

En Saber del mal y el bien y Peor está que estaba son los graciosos, con su característica libertad de actuación, quienes rompen la ilusión escénica y se dirigen al público para invitarlo a marcharse. Estas intervenciones de García y Camacho, muy relacionadas con los apartes, participan del espíritu lúdico e irónico que caracteriza a las comedias de la época. En la primera, García interpela a "vuesas mercedes» y les insta a que abandonen el lugar sin prisas y a que no critiquen la comedia para que de ese modo otros vayan a verla al día siguiente. Por tanto, la alusión no es solo a una audiencia presente en la representación, sino que se apela también a aquellos espectadores que serían partícipes de futuras puestas en escena, de acuerdo con la concepción comercial de las comedias calderonianas. En Peor está que estaba, el gracioso señala que «Ite, comedia est», adaptando al espectáculo teatral la locución Ite, missa est empleada en la Iglesia después de la bendición final usada para indicar el término de la celebración litúrgica ${ }^{12}$. Sin embargo, a diferencia de Saber del mal y el bien, en Peor está que estaba también contamos con la intervención de

${ }^{11}$ A propósito de este tipo de vocativos, señala Lobato, 2005, p. 261, que «constituyeron un poderoso resorte para llamar la atención de los destinatarios de la obra, involucrarles de forma personal y favorecer una buena recepción».

${ }^{12}$ Esta estructura latina en boca del gracioso indica con tono cómico el final de la obra. La asociación del humor con el cierre de la pieza tiene que ver con la búsqueda de la sonrisa en el espectador y la captatio benevolentiae, objetivos finales de cada uno de los elementos que estamos analizando en este trabajo. 
un noble, en este caso don César, quien interpela a la audiencia a través del sintagma "noble senado", alusión similar a la que se halla asimismo en Lances de amor y fortuna en boca de Rugero («senado, acabe con esto / Lances de amor y fortuna»). Dicha referencia busca elogiar al público para captar su benevolencia, segundos antes del veredicto final.

Siguiendo con este mismo afán lisonjeador, en La hija del aire, primera parte hallamos una doble alusión al auditorio, al que el gracioso menciona primeramente como "vuesas mercedes» y después como "corte ilustre». En Dicha y desdicha del nombre, sin embargo, don Félix interpela al Príncipe, personaje de la propia comedia (al que denomina, «señor»), que actúa como destinatario de la estereotipada fórmula de humilitas de la que nos hemos ocupado anteriormente, y, por tanto, figura como correlato del público en el escenario, como sucedía con el Rey en Amor, honor y poder. Más curioso es el caso de Gustos y disgustos son no más que imaginación, comedia en la cual el gracioso no se dirige al espectador, sino al lector: "Esta es verdadera historia, / de que saque el pío lector / que se estime lo que es propio».

A la luz de lo que se ha visto podríamos sacar la conclusión de que Calderón tuvo un especial interés en interactuar con el receptor de su obra en determinada época creativa de su vida, esto es, entre el año 1625 y 1640 aproximadamente, período en el que fueron compuestas todas estas comedias con excepción de Dicha y desdicha del nombre, que es mucho más tardía. Esta última, como hemos visto, no alude al público como colectivo, por lo cual quedaría al margen de la generalización que se está estableciendo. Así pues, no sería descabellado el afirmar que dicho elemento metateatral podría servir como herramienta para ayudar a la fijación de ciertas fechas de composición en casos dudosos.

Por último, cabe registrar las alusiones a vítores y aplausos que se recogen en 6 de las 73 comedias analizadas: En la vida todo es verdad y todo mentira, La púrpura de la rosa, El conde Lucanor, La niña de Gómez Arias, Basta callar y Andrómeda y Perseo. Nuevamente, estas inclusiones, que buscarían inclinar al público a la ovación, parecen responder al gusto de Calderón por ciertas formas en determinadas fechas. Concretamente, se puede apreciar cómo en sus obras de los años 50 y 60 , en contra de la tendencia a la humilitas, da por hecho que la representación finalizará con aplausos. Sirva de muestra En la vida todo es verdad y todo mentira ("Con cuyo aplauso se dé / fin a su historia...») o La púrpura de la rosa ("A cuyo aplauso festivo / fin a su fábula pone»), de 1659 y 1660, res- 
pectivamente, y compárese con las comedias compuestas a finales de los años 30 del siglo XVII, La niña de Gómez Arias ("Que perdonéis os suplico / sus errores y nos deis / de piedad siquiera un vítor») y Basta callar («Y ya que no merecemos / aplauso, sin mormurar, / basta callar»). No parece descabellado pensar que acaso el éxito alcanzado en este período de mayor madurez habría motivado al dramaturgo a suavizar la afectación en las fórmulas de modestia ante un reconocimiento incuestionable y generalizado de su valía como dramaturgo. En efecto, en esta época el autor había alcanzado y consolidado su éxito tanto en escenarios palaciegos como en los corrales.

En conclusión, en un marco tan artificioso y lúdico como el de la comedia de Siglo de Oro, se justifica la apertura de un canal de comunicación con la audiencia y la ruptura de la ilusión teatral, pues es frecuente que los distintos personajes reflexionen a lo largo de las obras sobre el proceso de creación y representación mediante diversos procedimientos muy recurrentes. El gusto por la reflexión metateatral es especialmente perceptible en el cierre de las comedias calderonianas, donde el dramaturgo madrileño despliega una serie de fórmulas que estarían bien asentadas en el horizonte de expectativas del público, expresadas por unos actores familiarizados con el recurso del aparte y versátiles a la hora de dirigir sus parlamentos de manera alterna a los propios participantes de la acción dramática o al auditorio.

En el presente estudio hemos recopilado y sistematizado dichos recursos, examinando casi la totalidad de las comedias del ingenio, esto es 73 obras, que disponen en este momento de una rigurosa y completa edición. Los componentes metateatrales, al lado de los cambios métricos y las prototípicas bodas - cuestiones ambas que no se han tratado en este artículo por razones de espacio-, pondrían el broche final a las obras funcionando como una especie de transición hacia el aplauso, pues desvían la escena del realismo e invitan al espectador a reaccionar de forma positiva ante el espectáculo.

Los aspectos analizados son relevantes no solo en tanto a su dimensión estética y a los datos arrojados sobre la relación del dramaturgo con su propia obra, sino por el valor que reviste para los investigadores el hecho de que Calderón haya optado por diferentes soluciones en diversos periodos bien delimitados de su creación literaria. En efecto, se aprecia cómo en las obras de madurez don Pedro se priva de señalarse a sí mismo y al público al final de sus comedias, al contrario de lo que hacía en 
las primeras décadas de su producción, acaso guiado por las ansias de un reconocimiento y aceptación que más tarde alcanzaría. Esta evolución cronológica en la selección de fórmulas estereotipadas de cierre motiva, entonces, que el análisis de los elementos metateatrales de las comedias calderonianas se convierta en una herramienta útil a la hora de enfrentarse, por ejemplo, con ciertas obras de datación dudosa. 


\section{BiBLIOGRAFÍA}

Avellaneda, Alonso, El Quijote apócrifo, ed.Alfredo Rodríguez López-Vázquez, Madrid, Cátedra, 2011.

Bravo Villasante, Carmen, «La realidad de la ficción, negada por el gracioso», Revista de Filología Española, 28, 1944, pp. 264-268.

Calderón de la Barca, Pedro, Comedias, I. Primera parte de comedias, ed. Luis Iglesias Feijoo, Madrid, Biblioteca Castro, 2006.

Calderón de la Barca, Pedro, Comedias, II. Segunda parte de comedias, ed. Santiago Fernández Mosquera, Madrid, Biblioteca Castro, 2007.

Calderón de la Barca, Pedro, Comedias, III. Tercera parte de comedias, ed. Don W. Cruickshank, Madrid, Biblioteca Castro, 2007.

Calderón de la Barca, Pedro, Comedias, IV. Cuarta parte de comedias, ed. Sebastian Neumeister, Madrid, Biblioteca Castro, 2010.

Calderón de la Barca, Pedro, Comedias, V. Quinta parte de comedias, ed. José María Ruano de la Haza, Madrid, Biblioteca Castro, 2010.

Calderón de la Barca, Pedro, Comedias, VI. Sexta parte de comedias, ed. José María Viña Liste, Madrid, Biblioteca Castro, 2010.

Calderón de la Barca, Pedro, La selva confusa. Edición crítica y adaptación, ed. Erik Coenen, Kassel, Reichenberger, 2011.

Hermenegildo, Alfredo, Juegos dramáticos de la locura festiva: pastores, simples, bobos y graciosos del teatro clásico español, Palma de Mallorca, José J. de Olañeta, 1995.

Iglesias Feijoo, Luis, "Calderón y el humor", en Ayer y hoy de Calderón. Actas seleccionadas del Congreso Internacional celebrado en Ottawa, 4-8 de octubre de 2000, ed. José María Ruano de la Haza y Jesús Pérez Magallón, Madrid, Castalia, 2002, pp. 15-36.

Lobato, María Luisa, «Mosqueteros de la paz, árbitros de la comedia: las fórmulas de captatio benevolentiae en boca del gracioso", en La construcción de un personaje, el gracioso, ed. Luciano García Lorenzo, Madrid, Fundamentos, 2005, pp. 251-276.

PAiller, Claire, «El gracioso y los guiños de Calderón», en Risa y sociedad en el teatro español del Siglo de Oro, Paris, Centre National de la Recherche Scientifique, 1980, pp. 33-50.

Rubiera Fernández, Javier, La construcción del espacio en la comedia española del Siglo de Oro, Madrid, Arco Libros, 2005. 